\title{
Editorial
}

\section{A Changing of the Guard}

It is with deep regret that we announce the resignations of Associate Editors Alfred B. Kristofferson and Martha Teghtsoonian. Their contributions of both expertise and time have been of immeasurable importance in the movement of Perception \& Psychophysics to the forefront of psychological journals.

At the same time, we would like to welcome two new Associate Editors to the journal-Myron Braunstein of the University of California, Irvine, and Norma Graham of Columbia University. We are most fortunate that they have agreed to devote their time and expertise to the journal. 